\title{
ESTIMATING THE NORMALIZED JENSEN FUNCTIONAL
}

\author{
FlaVia CORINA Mitroi
}

Abstract. We establish upper and lower bounds for the normalized Jensen functional in the context of $\left(M_{[\varphi]}, A\right)$-convexity. In connection with these results, a refinement of the triangle inequality is proved.

Mathematics subject classification (2010): Primary 26B25, Secondary 26E60, 26 D15.

Keywords and phrases: Normalized Jensen functional, quasi-arithmetic means.

\section{REFERENCES}

[1] S. Abramovich, S. S. Dragomir, Normalized Jensen Functional, Superquadracity and Related Inequalities, Internat. Ser. Numer. Math. 157 (2009), 217-228.

[2] J. M. AlDAZ, Comparison of differences between arithmetic and geometric means, arXiv:1001.5055v1 (to appear in Tamkang J. of Math.).

[3] J. BARIĆ, M. Matić, J. PeCARIĆ, On the bounds for the normalized functional and Jensen-Steffensen inequality, Math. Inequal. Appl. 12 (2009), 413-432.

[4] S.S. Dragomir, Bounds for the normalised Jensen functional, Bull. Austral. Math. Soc. 74 (2006), 471-478.

[5] M. Kato, K.-S. SAIto AND T. TAMURA, Sharp triangle inequality and its reverse in Banach spaces, Math. Inequal. Appl. 10, 2 (2007), 451-460.

[6] A. Matković, J. PeČARIĆ, A variant of Jensen's inequality for convex functions of several variables, J. Math. Inequal. 1, 1 (2007), 45-51.

[7] F. C. MitroI, About the precision in Jensen-Steffensen inequality, An. Univ. Craiova Ser. Mat. Inform. 37, 4 (2010), 73-84.

[8] C. P. Niculescu, Convexity according to means, Math. Ineq. Applications 6 (2003), 571-579.

[9] S. Simić, On an upper bound for Jensen's inequality, J. Inequal. Pure Appl. Math. 10, 2 (2009), article 60. 